\title{
Molecular analysis of the role of two aromatic aminotransferases and a broad-specificity aspartate aminotransferase in the aromatic amino acid metabolism of Pyrococcus furiosus
}

\author{
DONALD E. WARD, ${ }^{1,2}$ WILLEM M. DE VOS ${ }^{1}$ and JOHN VAN DER OOST ${ }^{1,3}$ \\ ${ }^{1}$ Laboratory of Microbiology, Wageningen University, Hesselink van Suchtelenweg 4, NL-6703 CT Wageningen, The Netherlands \\ ${ }^{2}$ Present address: Department of Chemical Engineering, North Carolina State University, P.O. Box 7905, Raleigh, NC 27695, USA \\ ${ }^{3}$ Author to whom correspondence should be addressed (john.vanderoost@algemeen.micr.wag-ur.nl)
}

Received February 14, 2002; accepted June 11, 2002; published online July 12, 2002

Summary The genes encoding aromatic aminotransferase II (AroAT II) and aspartate aminotransferase (AspAT) from Pyrococcus furiosus have been identified, expressed in Escherichia coli and the recombinant proteins characterized. The AroAT II enzyme was specific for the transamination reaction of the aromatic amino acids, and uses $\alpha$-ketoglutarate as the amino acceptor. Like the previously characterized AroAT I, AroAT II has highest efficiency for phenylalanine $\left(k_{\mathrm{cat}} / K_{\mathrm{m}}=\right.$ $923 \mathrm{~s}^{-1} \mathrm{mM}^{-1}$ ). Northern blot analyses revealed that AroAT I was mainly expressed when tryptone was the primary carbon and energy source. Although the expression was significantly lower, a similar trend was observed for AroAT II. These observations suggest that both AroATs are involved in amino acid degradation. Although AspAT exhibited highest activity with aspartate and $\alpha$-ketoglutarate $\left(k_{\text {cat }} \sim 105 \mathrm{~s}^{-1}\right)$, it also showed significant activity with alanine, glutamate and the aromatic amino acids. With aspartate as the amino donor, AspAT catalyzed the amination of $\alpha$-ketoglutarate, pyruvate and phenylpyruvate. No activity was detected with either branched-chain amino acids or $\alpha$-keto acids. The AspAT gene ( $\operatorname{asp} C$ ) was expressed as a polycistronic message as part of the aro operon, with expression observed only when the aromatic amino acids were absent from the growth medium, indicating a role in the biosynthesis of the aromatic amino acids.

Keywords: phenylalanine, phenylpyruvate.

\section{Introduction}

Aminotransferases are pyridoxal 5'-phosphate (PLP)-dependent enzymes that catalyze the reversible transfer of an amino group, usually the $\alpha$-amino group of an amino acid, to an amino acceptor, usually an $\alpha$-keto acid such as $\alpha$-ketoglutarate. These enzymes have been divided into four subfamilies based on structural similarities (Mehta et al. 1993). Subfamily I comprises the aspartate, alanine, aromatic and histidinolphosphate aminotransferases. The best characterized enzyme of this subfamily is aspartate aminotransferase (AspAT), which catalyzes the conversion of the dicarboxylic $\alpha$-amino acids, L-aspartate and L-glutamate, with the corresponding $\alpha$-keto acids, $\alpha$-ketoglutarate and oxaloacetate (Christen and Metzler 1985). The AspAT enzyme is a homodimer comprising two $45 \mathrm{kDa}$ subunits, each subunit having one PLP covalently bound to a lysine residue through a Schiff base linkage. The crystal structure has been solved for AspATs from numerous sources and the active site residues identified (McPhalen et al. 1992, Okamoto et al. 1994, Nobe et al. 1998). Based on structural homologies, the AspATs are divided into two subgroups: one including AspATs from bacteria and eukaryotes, and the other including AspATs from bacteria and archaea (Jensen and $\mathrm{Gu}$ 1996).

Pyrococcus furiosus is a hyperthermophilic archaeon that grows optimally at $100{ }^{\circ} \mathrm{C}$ by the fermentation of various carbohydrates, including starch, glycogen, $\beta$-glucans, cellobiose and maltose, and by the breakdown of proteins and peptides (Fiala and Stetter 1986, Kengen et al. 1996). Although much is known about the fermentation of oligosaccharides such as cellobiose and maltose, there is a contrasting lack of insight concerning proteolytic fermentation. For example, the metabolism of the individual amino acids of $P$. furiosus has not been investigated in detail. It has been implied that the aromatic amino acids could serve as a source of ATP via substrate-level phosphorylation in P. furiosus (Mai and Adams 1994). It has been proposed that this occurs by the coordinated actions of an aromatic aminotransferase (AroAT), the indolepyruvate ferredoxin oxidoreductase (IOR) and an ADP-dependent acetyl-CoA synthetase, thereby generating the free acids and ATP (Mai and Adams 1996).

Pyrococcus furiosus is capable of synthesizing all three aromatic amino acids, distinguishing it from Pyrococcus abyssi, which appears to be auxotrophic for Phe and Tyr (Watrin et al. 1995), and Pyrococcus horikoshii, which requires Phe, Tyr and Trp (Gonzalez et al. 1998). It is anticipated that, in P. furiosus, specific aminotransferases are involved in the catalysis of the last step in the biosynthesis of Phe and Tyr. Two distinct aromatic aminotransferases have been identified in P. furiosus, 
of which one, AroAT I, has been biochemically characterized in detail (Andreotti et al. 1995). Recently, Matsui et al. (2000) isolated and solved the crystal structure of a second aromatic aminotransferase, AroAT II, from P. horikoshii. Similar to AspATs and AroATs from mesophilic sources, the P. horikoshii AroAT II is a homodimer with one PLP bound per subunit.

We report on the identification and functional expression of the $P$. furiosus AspAT in Escherichia coli and its biochemical characterization. The AroAT II was also expressed and characterized in further detail. In addition, transcriptional analyses were performed in $P$. furiosus showing that the three aminotransferases, AroAT I, AroAT II and AspAT, are each regulated differently at the level of transcription. The combined biochemical and transcriptional results provide insight into the potential role of the distinct pyrococcal aminotransferases in both the catabolism and biosynthesis of aromatic amino acids.

\section{Materials and methods}

\section{Growth of microorganisms}

Pyrococcus furiosus (DSM 3638) was grown either in a sea salts medium (SSM) (Ward et al. 2000) or a chemically defined medium (CDM). The CDM medium was made as described by Kengen et al. (1993) except that yeast extract was replaced by the 20 amino acids at a final concentration of $0.25 \mathrm{mM}$. Cellobiose $(10 \mathrm{mM})$, maltose $(10 \mathrm{mM})$, pyruvate $(40 \mathrm{mM})$ or tryptone $\left(5 \mathrm{~g}^{-1}\right)$ were included as the primary carbon source. Escherichia coli strains BL21( $\lambda$ DE3) and XL-1 were grown at $37{ }^{\circ} \mathrm{C}$ in Luria-Bertani medium, and when required, kanamycin $\left(50 \mu \mathrm{g} \mathrm{ml}^{-1}\right)$ was included.

Cloning and expression of the genes encoding aromatic aminotransferase II and aspartate aminotransferase

The genes coding for AroAT II (PF1187250) and AspAT (PF1582969) were amplified from $P$. furiosus genomic DNA with the oligonucleotides BG550 (5'-CCATGGCACTTAGCGACAAGC) and BG551 (5'-CGCGGGATCCCTCAGATGAGCTTTTTCTCC) for AroAT II, and BG810 (5'-CGCGCCATGGCCTTCAACGTTTATGAGCTATTTAATAAG) and BG783 (5'-CGCGGGATCCTTATTGTGATTCGCATTCTGCTACCTCC) for AspAT. The N-terminus of the AroAT II was based on the N-terminal sequence of the Thermococcus litoralis AroAT II (Andreotti et al. 1994), the presence and proper spacing of a ribosomal binding site (RBS) and the annotation from the genome sequence. The N-terminus of the AspAT was identified based on the presence and proper spacing of the RBS, annotation from the genome sequence and its agreement with the AspAT identified from Thermococcus kodakaraensis (Accession Number BAA75925). The oligonucleotides BG550 and BG810 contain NcoI sites, whereas BG551 and BG783 contain BamHI sites. The PCR amplification was carried out with $P f u$ polymerase (Stratagene) and the resulting $1.2 \mathrm{~kb}$ (AroAT II) and $1.0 \mathrm{~kb}$ (AspAT) PCR products were cloned into pET-24d using the NcoI and BamHI sites. The recombinant plasmids, pLUW771 (AroAT II) and
pLUW790 (AspAT), were transformed into Escherichia coli BL21( $\lambda$ DE3). For expression of the recombinant enzymes, E. coli $\mathrm{BL} 21(\lambda \mathrm{DE} 3)$, harboring the appropriate plasmid, was grown in 11 of medium at $37^{\circ} \mathrm{C}$ for $16-18 \mathrm{~h}$, at which point the cells were harvested for purification of the recombinant enzyme.

\section{Purification of the recombinant aminotransferases}

The recombinant AroAT II (rAroAT II) was purified by a 2-step method. A 1.0-1 overnight culture of E. coli BL21 ( $\lambda$ DE3), harboring pLUW771, was harvested and resuspended in $10 \mathrm{ml}$ of $20 \mathrm{mM}$ Tris- $\mathrm{Cl}$ ( $\mathrm{pH} 7.8$ ), $0.1 \mathrm{mM}$ pyridoxal $5^{\prime}$ phosphate and $2 \mathrm{mM} \alpha$-ketoglutarate. The cells were lyzed by sonication and the cellular debris removed by centrifugation. The supernatant was incubated at $80^{\circ} \mathrm{C}$ for $15 \mathrm{~min}$ and the denatured $E$. coli proteins were removed by centrifugation (13,000 $\mathrm{g}$ for $30 \mathrm{~min})$. The supernatant $(12 \mathrm{ml})$ was applied to a Mono-Q column equilibrated with Tris buffer and eluted with a linear gradient of 0 to $1.0 \mathrm{M} \mathrm{NaCl}$ at a flow rate of $0.5 \mathrm{ml}$ $\mathrm{min}^{-1}$. The rAroAT II eluted between 0.05 and $0.12 \mathrm{M} \mathrm{NaCl}$. The recombinant protein was stored at $4{ }^{\circ} \mathrm{C}$. The rAspAT was purified using a similar procedure and eluted from the MonoQ at $\mathrm{NaCl}$ concentrations between 0.35 and $0.42 \mathrm{M}$.

\section{Enzyme assays}

Aspartate aminotransferase activity was routinely assayed at $50{ }^{\circ} \mathrm{C}$, because of the instability of oxaloacetate at elevated temperatures. The amount of aspartate converted to oxaloacetate was measured indirectly by the NADH-dependent conversion of oxaloacetate to malate catalyzed by malate dehydrogenase $(\mathrm{MDH})$. The AspAT reaction mixture $(1 \mathrm{ml})$ contained $20 \mathrm{mM}$ Tris ( $\mathrm{pH} 7.8$ ), $50 \mu \mathrm{M}$ pyridoxal $5^{\prime}$-phosphate, $20 \mathrm{mM} \alpha$-ketoglutarate, $50 \mathrm{mM}$ L-aspartate, $0.2 \mathrm{mM} \mathrm{NADH}$ and $3 \mathrm{U} \mathrm{MDH}$ from beef muscle. The reaction was started by the addition of the AspAT, and enzyme activity was monitored by the decrease in absorbance at $340 \mathrm{~nm}$. One unit of AspAT or $\mathrm{MDH}$ is defined as the amount of enzyme that catalyzes the oxidation of $1 \mu \mathrm{mol} \mathrm{NADH} \mathrm{min}^{-1}$. The activity with glutamate and oxaloacetate as substrates was determined indirectly by the NADH-dependent conversion of $\alpha$-ketoglutarate to glutamate, catalyzed by glutamate dehydrogenase (GDH). The reaction mixture $(1 \mathrm{ml})$ contained $20 \mathrm{mM}$ Tris $(\mathrm{pH} 7.8), 50 \mu \mathrm{M}$ pyridoxal 5'-phosphate, $20 \mathrm{mM}$ oxaloacetate, $50 \mathrm{mM}$ L-glutamate, $0.2 \mathrm{mM} \mathrm{NADH}, 50 \mathrm{mM} \mathrm{NH}_{4} \mathrm{Cl}$ and $15 \mathrm{U} \mathrm{GDH}$.

Alanine aminotransferase activity was assayed at $80{ }^{\circ} \mathrm{C}$ as described previously by Ward et al. (2000). The amount of alanine converted to pyruvate was measured by the conversion of NADH in a separate lactate dehydrogenase (LDH) assay at $30{ }^{\circ} \mathrm{C}$. The AlaAT reaction mixture $(1 \mathrm{ml})$ contained $50 \mathrm{mM}$ MOPS (pH 7.2), $100 \mathrm{mM} \mathrm{KCl,} 50 \mu \mathrm{M}$ pyridoxal 5'-phosphate, $20 \mathrm{mM} \alpha$-ketoglutarate and $50 \mathrm{mM} \mathrm{L}$-alanine. The reaction mixture was pre-incubated at $80{ }^{\circ} \mathrm{C}$ for 5 min and the reaction started by the addition of enzyme. The reaction was stopped by snap freezing in an ice/ethanol bath. Samples were taken $(5-100 \mu \mathrm{l})$ and added to the LDH assay, which contained $100 \mathrm{mM}$ potassium phosphate $(\mathrm{pH}=7.0), 0.2 \mathrm{mM} \mathrm{NADH}$ and $3 \mu \mathrm{LDH}$ from beef muscle. One unit of AlaAT or LDH is de- 
fined as the amount of enzyme that catalyzes the oxidation of $1 \mu \mathrm{mol}$ NADH $\mathrm{min}^{-1}$.

Aromatic aminotransferase activity was determined as described by Andreotti et al. (1994). The assay involved the detection of an arsenate-catalyzed formation of aromatic $\alpha$-ketoacid-enol-borate complexes. The assays were carried out in a volume of $800 \mu \mathrm{l}$, containing $50 \mathrm{mM}$ MOPS (pH 7.2), $20 \mathrm{mM}$ phenylalanine and $5 \mathrm{mM} \alpha$-ketoglutarate. The reaction mixture was pre-incubated at $80{ }^{\circ} \mathrm{C}$ for $5 \mathrm{~min}$ and the reaction started by the addition of enzyme. The reaction was stopped by the addition of $20 \%(\mathrm{w} / \mathrm{v})$ trichloroacetic acid, to a final concentration of $4 \%(\mathrm{w} / \mathrm{v})$, rapidly cooled on ice and centrifuged. A $100-\mu l$ sample of the supernatant was diluted with $500 \mu$ of $1 \mathrm{M}$ boric acid ( $\mathrm{pH}$ 6.5) and $1 \mathrm{M}$ sodium arsenate and incubated for $25 \mathrm{~min}$ at room temperature. The amount of phenylpyruvate-enol-borate was measured at $300 \mathrm{~nm}$ and estimated based on an extinction coefficient of $7100 \mathrm{M}^{-1} \mathrm{~cm}^{-1}$.

\section{RNA isolation, northern blot analysis and primer extension}

Isolation of total RNA from $P$. furiosus and northern blot analyses were carried out as described by Ward et al. (2000). The 5' end of the $a s p C$, tyrB and tyrC genes were mapped using the oligonucleotides 5'-TCTCCCCTTTTTAGAGAATTTATGG, 5'-TTCTGAGGCTTTCATCTTTAGAGC and 5'-AAAGTCGGGCTCTCCAATTCCC. The oligonucleotides were labeled with the fluorescent label IRD800 by the manufacturer (MWG-BIOTECH AG, Ebersberg, Germany). The primer extension reaction was carried out using the Reverse Transcription System (Promega) according to the manufacturer's instructions with the following modifications: 2.0 pmol of oligonucleotide was hybridized with $20 \mu \mathrm{g}$ of total RNA in $10 \mu \mathrm{l}$ of the supplied buffer by heating at $70^{\circ} \mathrm{C}$ for $10 \mathrm{~min}$, before allowing to cool to room temperature. The reaction was started by the addition of dNTPs $(1 \mathrm{mM}), \mathrm{MgCl}_{2}(5 \mathrm{mM}), \mathrm{RNAsin}$ $(20 \mathrm{U})$ and AMV-RT (22.5 U) in a final volume of $20 \mu \mathrm{l}$. The reaction was incubated at $45^{\circ} \mathrm{C}$ for $30 \mathrm{~min}$, at which point the volume was adjusted to $50 \mu \mathrm{l}$ with $10 \mathrm{mM}$ Tris- $\mathrm{HCl}(\mathrm{pH} 8.5)$, $1 \mu \mathrm{l}$ of RNase A $\left(5 \mathrm{mg} \mathrm{ml}^{-1}\right)$ was added, and the mixture incubated at $37{ }^{\circ} \mathrm{C}$ for $10 \mathrm{~min}$. The RNA were precipitated with ethanol and the pellets dissolved in $5 \mu \mathrm{l}$ of loading buffer; $1 \mu \mathrm{l}$ was subjected to electrophoresis on a sequencing gel in parallel with a sequencing reaction obtained with the same oligonucleotide. The following oligonucleotide pairs were used to generate probes for northern blot analyses: for the AroAT I,
BG720 (5'-CAAAAGTTGACATAATGATTACA) and BG721 (5'-GTCAACACTCTGCTTTGCAATCTC), and for the AroAT II, BG722 (5'-GATCCCAAGTCCAATGTTCGT GAG) and BG723 (5'-CAGCTTCTCTCGTCTCTTAGTGC). Oligonucleotides BG846 (5'-GGTAATTGTTGGGCCTGG AGCC) and BG847 (5'-CCCAGCCCTTTGAACGAAAGGA GG) were used for AspAT analysis.

\section{Results \\ Comparison of the genome organization and primary structure of AspAT and AroATs in Pyrococcus}

Based on the N-terminal sequence previously determined by Andreotti et al. (1995), the gene encoding the AroAT I (tyrB) was identified and contains the gene identifier PF0121. A BLAST search with the pyrococcal AlaAT (Ward et al. 2000) of the $P$. furiosus genome (http://www.genome.utah.edu) revealed two putative paralogs (PF1253 and PF1702). To study their function, the latter genes were cloned, overexpressed, and the corresponding enzymes were characterized (see below) and identified as AroAT II (tyrC) and AspAT ( $a s p C)$.

The $\operatorname{asp} C$ gene is located in the $13 \mathrm{~kb}$ aro gene cluster in $P$. furiosus, and the trp gene cluster is located immediately downstream and is transcribed in the opposite orientation (Figure 1). Directly upstream of $\operatorname{aspC}$ is a gene that encodes a putative monofunctional chorismate mutase (aroQ) and downstream is a gene that encodes a putative prephenate dehydrogenase (tyrA). The AroQ was $30 \%$ identical to the monofunctional chorismate mutase identified and characterized in Methanococcus jannaschii (MacBeath et al. 1998), whereas the TyrA exhibited significant identity (24-34\%) to prephenate dehydrogenases from both mesophilic and thermophilic sources. Comparison to the $P$. abyssi genome reveals that the $\operatorname{aro} Q, \operatorname{asp} C$ and tyrA genes are missing from the aro gene cluster. Moreover, homologs to aro $Q$, aspC or tyrA could not be identified on the chromosome of $P$. abyssi. The G $+\mathrm{C}$ content (38\%) and codon usage of aro $Q$, aspC and tyrA are in good agreement with the rest of the $P$. furiosus genome, and suggest a deletion rather than an insertion. Analysis of the surrounding sequence revealed no elements that might be involved in a deletion or insertion event, such as inverted repeats or IS-elements. Pyrococcus horikoshii lacks both the aro and trp operons, including the $\operatorname{aro} Q, \operatorname{asp} C$ and tyrA cluster. Similar

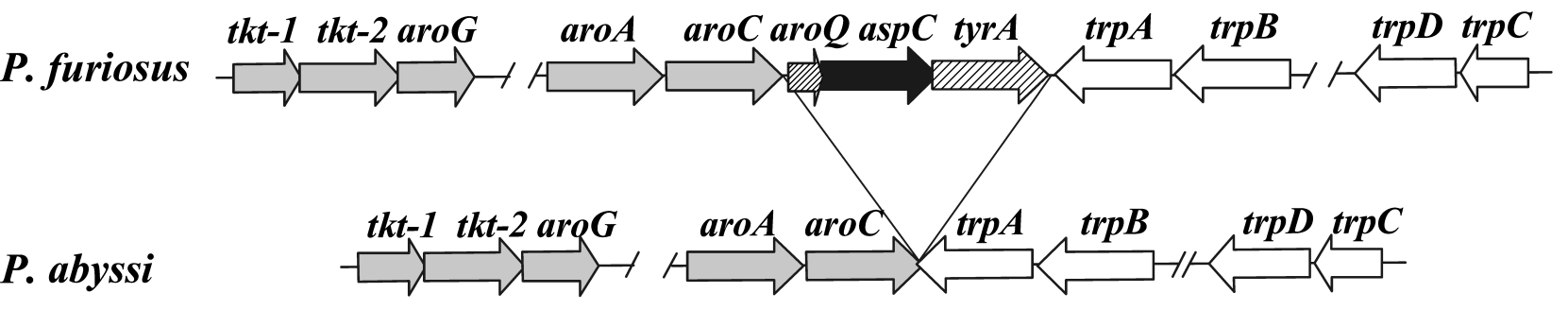

Figure 1. Molecular organization of the aro gene cluster and the AspAT (aspC) in $P$. furiosus and $P$. abyssi: aro $Q$, putative monofunctional chorismate mutase; aspC, aspartate aminotransferase; ty $\mathrm{r} A$, putative prephenate dehydrogenase. 
to $P$. abyssi, an $a s p C$ homolog was not identified elsewhere on the chromosome. In an effort to better understand the distribution in the Thermococcales, southern blot analysis was carried out with $\operatorname{aspC}$ as a probe. The $\operatorname{aspC}$ was identified in single copy in both $P$. furious and $P$. woesei, but was absent from P. abyssi, P. horikoshii, T. profundus, T. peptonophilus, T. barophilus and T. stetteri (data not shown). However, an aspC homolog is present in T. kodakaraensis (Accession Number BAA75925). Neither tyrB nor tyrC appeared to be organized in an operon-like structure. Homologs of $t y r B$ and tyrC were easily identified in both $P$. abyssi (PAB2227 and PAB0525) and P. horikoshii (PH0207 and PH1371).

The structural tyrC gene encoding the AroAT II consists of $1203 \mathrm{bp}$ and encodes a protein of 400 residues with a predicted molecular mass of $45.5 \mathrm{kDa}$. The structural $\operatorname{aspC}$ gene encoding the AspAT consists of $1041 \mathrm{bp}$ and encodes a protein of 346 residues with a predicted molecular mass of $39 \mathrm{kDa}$. The AroAT I, AroAT II and AspAT all share similarities to the subfamily $\mathrm{I} \gamma$ and $\mathrm{I} \delta$ aminotransferases (Mehta et al. 1993, Jensen and $\mathrm{Gu}$ 1996), which is in contrast to the previously characterized pyrococcal AlaAT, which clearly belongs to the subfamily I $\delta$ (Figure 2). BLAST and TFASTA analyses of the
AspAT and AroATs revealed the highest degree of identity to the thermophilic AspATs of the subfamily I $\gamma$, and for this reason all three have been classified within the subfamily $\mathrm{I} \gamma$. The 11 invariant residues involved in binding of the substrate or the cofactor pyridoxal 5'-phosphate were conserved in all three aminotransferases.

\section{Purification and characterization of rAspAT and rAroAT II}

The rAspAT was purified 19-fold with a yield of $65 \%$ and a specific activity of $158 \mathrm{U} \mathrm{mg}^{-1}$ with aspartate and $\alpha$-ketoglutarate as substrates (Table 1). The rAspAT had a subunit molecular weight of $42 \mathrm{kDa}$ and the molecular mass of the native enzyme was $80 \mathrm{kDa}$ as determined by SDS-PAGE and gel filtration, respectively, suggesting that the active form of the enzyme is a homodimer similar to AspATs from both mesophilic and thermophilic sources. The kinetic parameters were determined at $50{ }^{\circ} \mathrm{C}$ and the results are summarized in Table 1 . The substrate specificity of the rAspAT was determined with saturating amounts of the amino acids $(20 \mathrm{mM})$ and $\alpha$-ketoglutarate $(10 \mathrm{mM})$ as the amino acceptor. The enzyme exhibited broad substrate specificity and was active with aspartate, alanine and all three aromatic amino acids (Table 2).

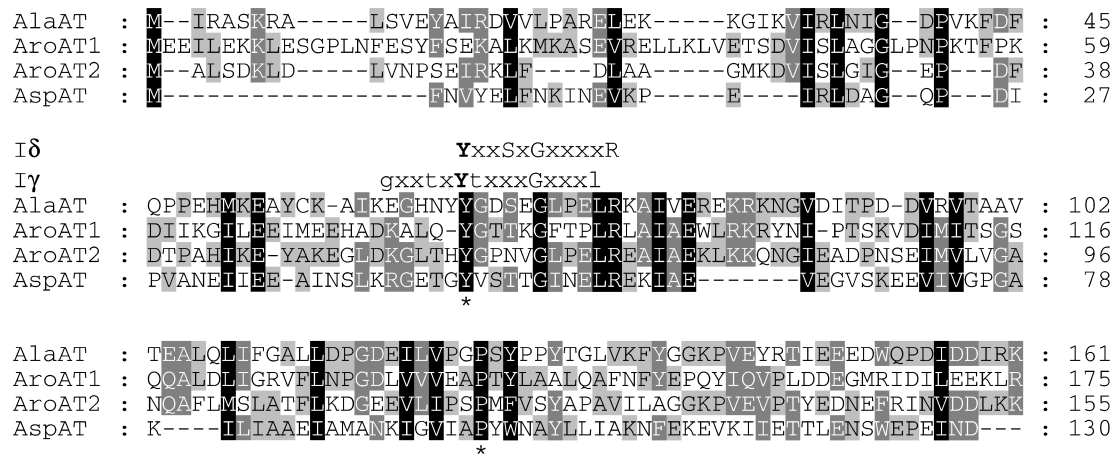

$I \delta$
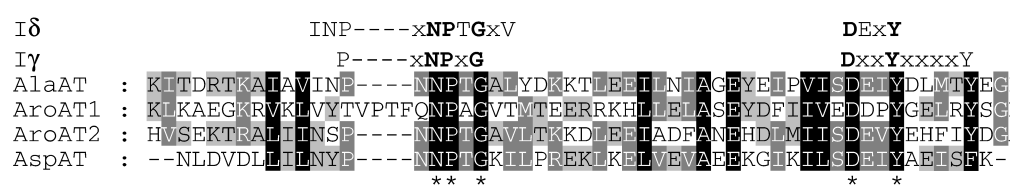

DEXY

$I \delta$
$I \gamma$

I $\gamma$

ArOAT1

ArOAT2

AspAT

AlaAt

ArOAT1

AspAT
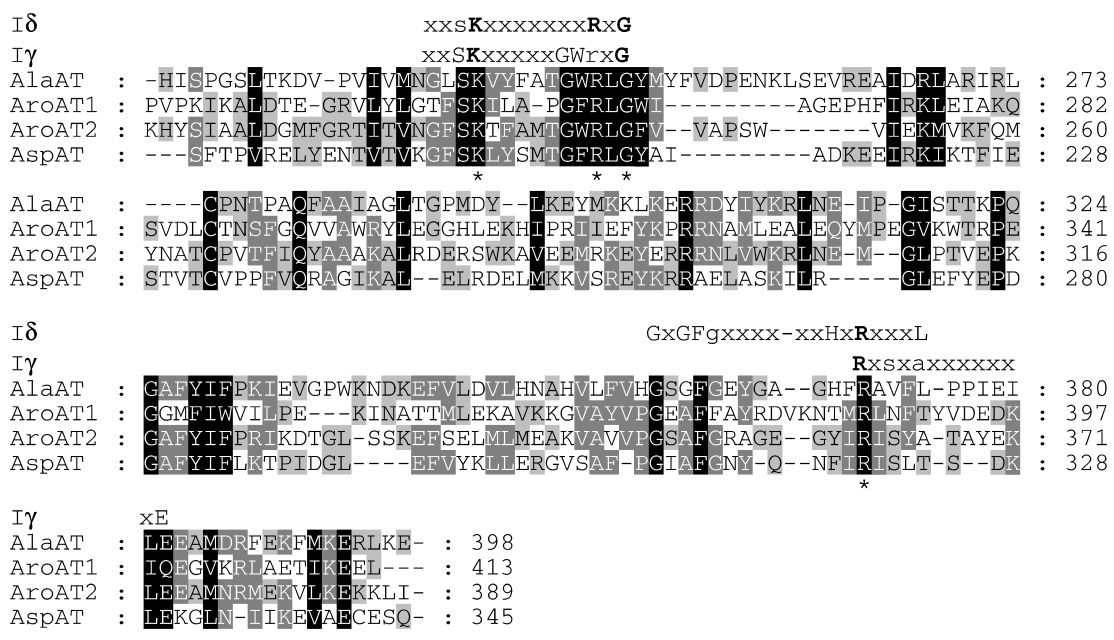

Figure 2. Multiple sequence alignment of $P$. furiosus AlaAT, AroAT I,

AroAT II and AspAT. The alignment was performed with Clustal W. Invariant residues found within the subclass I aminotransferases are designated with an asterisk. The motifs associated with subfamilies $I \delta$ and $I \gamma$ aminotransferases are also shown. 
Table 1. Kinetic parameters of Pyrococcus furiosus rAroAT II and rAspAT. ${ }^{1}$

\begin{tabular}{llllll}
\hline Enzyme & Substrate & Apparent $K_{\mathrm{m}}(\mathrm{mM})$ & Specific activity $\left(\mu \mathrm{mol} \mathrm{min} \mathrm{mg}^{-1}\right)$ & $k_{\mathrm{cat}}\left(\mathrm{s}^{-1}\right)$ & $k_{\mathrm{cat}} / K_{\mathrm{m}}\left(\mathrm{s}^{-1} \mathrm{mM}^{-1}\right)$ \\
\hline \multirow{2}{*}{ rAroAT II } & Phenylalanine & 1.3 & 1600 & 1200 & 923 \\
& Tyrosine & 2.6 & 1560 & 1130 & 434 \\
& Tryptophan & 3.4 & 1960 & 1420 & 418 \\
& $\alpha$-Ketoglutarate & 0.9 & 158 & 105 & 25 \\
\multirow{2}{*}{ rAspAT } & Aspartate & 4.2 & & & \\
& $\alpha$-Ketoglutarate & 0.46 & & & \\
\hline
\end{tabular}

${ }^{1}$ For the amino acids, $5 \mathrm{mM} \alpha$-ketoglutarate was used as the amino acceptor. For $\alpha$-ketoglutarate, $20 \mathrm{mM}$ phenylalanine or aspartate was used as the amino donor. The AspAt was assayed at $50{ }^{\circ} \mathrm{C}$ and the AroAT II was assayed at $80^{\circ} \mathrm{C}$.

As with all AspATs, the enzyme was able to use glutamate and oxaloacetate as substrates, and had a specific activity of $46 \mathrm{U}$ $\mathrm{mg}^{-1}$. Using aspartate as the amino donor, the enzyme was also capable of utilizing $\alpha$-ketoglutarate, pyruvate and phenylpyruvate as amino acceptors (Table 2). No activity was observed with the branched-chain $\alpha$-keto acids $\alpha$-ketoisocaproate or $\alpha$-keto- $\beta$-methylvalerate.

The rAroAT II was purified 27-fold with a yield of $74 \%$ and a specific activity of $1600 \mathrm{U} \mathrm{mg}^{-1}$ with phenylalanine and $\alpha$-ketoglutarate as substrates (Table 1). The purified rAroAT II migrated as a single band in an SDS-PAGE with an apparent molecular mass of $46 \mathrm{kDa}$. The molecular mass of the native enzyme was $95.4 \mathrm{kDa}$ as determined by gel filtration, suggesting that the active form of the enzyme exists as a dimer of identical subunits. This resembles the AroATs from E. coli (Hayashi et al. 1993), P. denitrificans (Oue et al. 1997) and T. litoralis (Andreotti et al. 1994), and the AroAT I from P. furiosus (Andreotti et al. 1995), which exist as homodimers. The kinetic parameters of the AroAT II were determined at $80{ }^{\circ} \mathrm{C}$ and the results are summarized in Table 1 . There was no indication of substrate inhibition as was found with the AroAT from Klebsiella aerogenes (Paris and Magasanik 1981). Similar to the AroATs from M. aeolicus (Xing and Whitman 1992)

Table 2. Substrate specificity of rAspAT from P. furiosus. The amino acids $(20 \mathrm{mM})$ were assayed with $5 \mathrm{mM} \alpha$-ketoglutarate as the amino acceptor, and the $\alpha$-ketoacids ( $5 \mathrm{mM}$ ) were assayed with $20 \mathrm{mM}$ aspartate as the amino donor.

\begin{tabular}{ll}
\hline Substrate & Relative activity $(\%)$ \\
\hline Aspartate & 100 \\
Glutamate & 30 \\
Alanine & 1.2 \\
Phenylalanine & 1.0 \\
Tyrosine & 0.6 \\
Tryptophan & 1.0 \\
$\alpha$-Ketoglutarate & 100 \\
Pyruvate & 8 \\
Phenylpyruvate & 3 \\
$\alpha$-Ketoisovalerate & $<0.01$ \\
$\alpha$-Keto- $\beta$-methylvalerate & $<0.01$ \\
\hline
\end{tabular}

and T. litoralis (Andreotti et al. 1994) and the AroAT I from $P$. furiosus (Andreotti et al. 1995), AroAT II was active with all three aromatic amino acids and displayed low activity with the amino acids alanine and aspartate (Table 3). Furthermore, the AroAT II from $P$. furiosus was almost identical to that from T. litoralis.

\section{Regulation of AroAT I, AroAT II and AspAT}

To elucidate the regulation of the individual aminotransferases, $P$. furiosus was grown with cellobiose $(10 \mathrm{mM})$, pyruvate $(40 \mathrm{mM})$ or tryptone $\left(5 \mathrm{~g} \mathrm{l}^{-1}\right)$ as the primary carbon and energy source. Because AspAT is believed to play a role in the biosynthesis of aromatic amino acids, we used a chemically defined medium containing all the amino acids, except for the aromatic amino acids, and $10 \mathrm{mM}$ cellobiose as the primary carbon source. The three aromatic amino acids $(0.25 \mathrm{mM}$ final) were added $(\mathrm{C}+)$ or left out $(\mathrm{C}-)$ of the culture. Early exponential-phase cells were used for assay of enzyme activities in crude extracts and for isolation of total RNA for transcriptional analyses. Internal fragments of the tyrB, tyrC and aspC genes were generated by PCR, labeled and used as probes for northern blot analyses. Both $t y r B$ and $t y r C$ were expressed as a single, monocistronic 1.7-kb mRNA species consisting of only the $t y r B$ or $t y r C$ genes (Figure $3 \mathrm{~A}$ ). Expression of the tyrB gene was 5 -fold higher when $P$. furiosus was grown with tryptone as the primary carbon source compared with cellobiose as the carbon source. There was also a 2 -fold in-

Table 3. Substrate specificity of AroATs from Pyrococcus furiosus and Thermococcus litoralis, expressed as relative maximal activity (\%). Abbreviation: $\mathrm{nd}=$ not determined.

\begin{tabular}{lcccc}
\hline Substrate & AroAT I $^{1}$ & AroAT II & AroAT I $^{2}$ & AroAT II $^{2}$ \\
\hline Alanine & nd & 1.0 & 0.8 & 0.2 \\
Aspartate & nd & 0.1 & $<0.1$ & 0.1 \\
Phenylalanine & 100 & 84 & 100 & 82 \\
Tyrosine & 28 & 79 & 44 & 56 \\
Tryptophan & 24 & 100 & 29 & 100 \\
\hline
\end{tabular}

1 Values for the P. furiosus AroAT I are from Andreotti et al. (1995).

${ }^{2}$ Values for the T. litoralis AroATs are from Andreotti et al. (1994). 
Table 4. Activities of AroATs and AspAT in crude extracts of P. furiosus grown on various carbon sources. Either $20 \mathrm{mM}$ aspartate or phenylalanine, and $5 \mathrm{mM} \alpha$-ketoglutarate were used as substrates.

\begin{tabular}{lll}
\hline Carbon source & AspAT $\left(\mathrm{U} \mathrm{mg}^{-1}\right)$ & $\operatorname{AroAT}\left(\mathrm{U} \mathrm{mg}^{-1}\right)$ \\
\hline $10 \mathrm{mM}$ Cellobiose & 0.5 & 2.9 \\
$40 \mathrm{mM}$ Pyruvate & 0.6 & 5.7 \\
$5 \mathrm{~g} \mathrm{l}^{-1}$ Tryptone & 0.8 & 8.7 \\
\hline
\end{tabular}

crease in tyrB expression in pyruvate-grown cells compared with cellobiose-grown cells. Although the overall expression was lower, a similar trend was observed in the case of tyrC (Figure 3A). Similar results were observed for the catalytic activity of the AroATs in cell extracts with 3-fold higher total AroAT activity in tryptone-grown cells and 2-fold higher in pyruvate-grown cells compared with cellobiose-grown cells (Table 4). The presence or absence of the aromatic amino acids had no effect on the transcription of either tyrB or $t y r C$. This may indicate a global regulation of amino acid catabolism (like the leucine response in $E$. coli) rather than a specific induction of aromatic amino acids.

A single major, apparent mRNA $5^{\prime}$ end was identified upstream of tyrB by primer extension (Figure 3B). A minor $5^{\prime}$ end was also observed five base pairs downstream of the major start site. This minor start site was observed under all tested conditions, indicating that it was not caused by degradation. However, in all conditions tested it was also the minor promoter. Analysis of the upstream sequence identified features common to archaeal promoters. These include the TATA-box located 25 bp upstream of the transcription initiation site, and the TFB-responsive element or BRE element (Bell et al. 1999). Comparison of the tyrB promoter regions between $P$. furiosus, $P$. abyssi and $P$. horikoshii revealed $60 \%$ identity over the entire $120 \mathrm{bp}$ and $100 \%$ identity at the TATA and BRE sites (Figure 3C). Furthermore, a 14-bp inverted repeat was identified upstream of the TATA and BRE sites that is also highly conserved in all three promoters. This high degree of conservation among the $t y r B$ promoters suggests a similar mode of regulation in $P$. abyssi and $P$. horikoshii.

The AroAT II (tyrC) appears to be expressed constitutively at a low level regardless of the carbon source. The highest total
A.

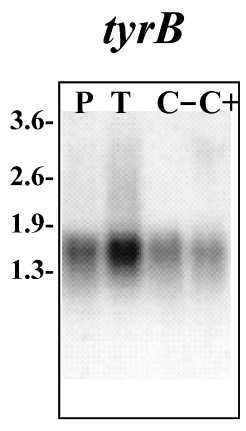

C.

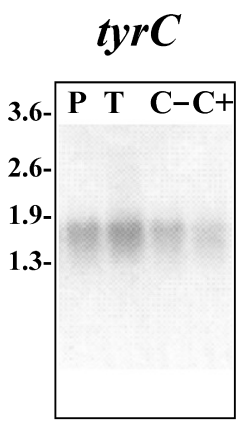

B.

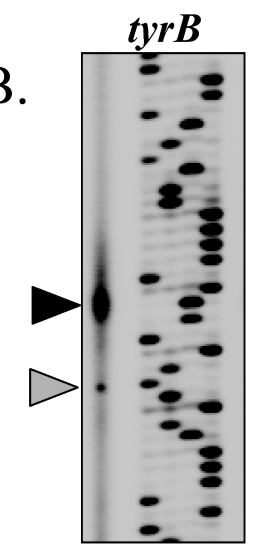

ACGT

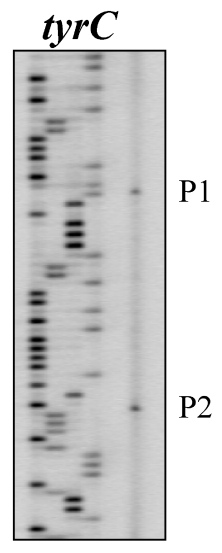

ACGT

\section{tyrB promoter}

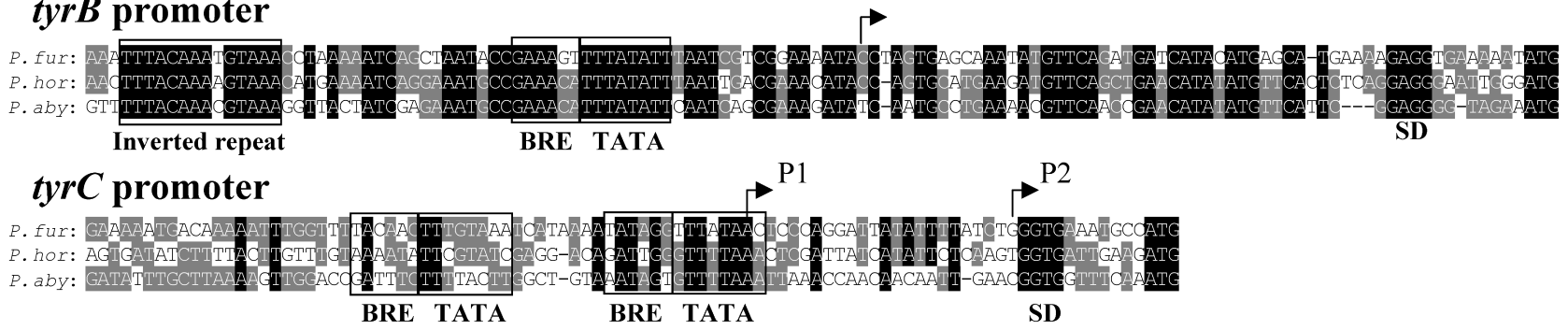

Figure 3. (A) Northern blot analysis of the P. furiosus tyrB (AroAT I) and tyrC (AroAT II) transcripts. Pyrococcus furiosus was grown with the following compounds as the primary carbon and energy source: $10 \mathrm{mM}$ cellobiose (C), $40 \mathrm{mM}$ pyruvate (P), or $5 \mathrm{~g}^{-1}$ tryptone (T). Pyrococcus furiosus was also grown in a chemically-defined medium with cellobiose as carbon source in the presence $(\mathrm{C}+)$ and absence $(\mathrm{C}-)$ of the aromatic amino acids. (B) Identification of the transcriptional start site for the $t y r B$ and $t y r C$ by primer extension analysis; arrows indicate major and minor primer extension product. (C) Sequence of the $t y r B$ and $t y r C$ promoter regions and alignment to the tyr $B$ and tyr $C$ promoter regions from $P$. abyss $i$ and $P$. horikoshii. The transcriptional start site as determined by primer extension analysis is designated by an arrow. The TATA and BRE sequences are boxed. The putative ribosome binding site (S/D) is shown and the final ATG of each sequence is the first codon of each gene. 
AroAT activity observed in cell extracts was also found in tryptone. Because of the overlapping activities of AroAT I and AroAT II, it was impossible to determine if one enzyme was responsible for the increase in activity, or if both enzymes were involved. Based on northern blot analysis, we conclude that AroAT I is responsible for the observed increase in activity. For tyrC, two transcription start sites were identified by primer extension (Figure 3B). Both the TATA and BRE sequences were identified upstream of Promoter 1 (P1) and Promoter 2 (P2). The relative levels of expression from both promoters were identical regardless of the carbon source (data not shown). Comparison of the promoter regions of tyrC in P. furiosus, $P$. abyssi and P. horikoshii revealed some conservation around the BRE and TATA sequences of P2, whereas little identity was found in the elements around P1.

Expression of the $a s p C$ gene was detected only when the cells were grown in the absence of the aromatic amino acids. Two transcripts of about 2.5 and $1.8 \mathrm{~kb}$ were identified using an internal fragment of $\operatorname{aspC}$ as a probe (Figure 4A). Assuming transcription initiation just upstream of $\operatorname{aro} Q$ (see be- low), the transcript site suggests co-transcription of the aro $Q-$ aspC-tyrA gene cluster, which is about $1.7 \mathrm{~kb}$ in length. The larger transcript is most likely the result of read-through. The addition of tryptone or the aromatic amino acids abolished expression of the aspC transcripts. A low basal level of AspAT activity was found in all extracts regardless of the carbon source (Table 4). This activity could be due to overlapping activities found in AroAT II and AlaAT. The transcriptional start site of the aspC transcript was mapped at a thymine base $46 \mathrm{bp}$ upstream of the $\operatorname{aro} Q$ translational initiation site. Potential TATA and BRE sequences were identified in the promoter region. The leader sequence was longer than usually observed in $P$. furiosus, because the transcriptional start site is often found within a few base pairs of the ribosome binding site. A ribosome binding site located upstream of aro $Q$ is absent in $P$. furiosus. The predicted translational start site is, however, in good agreement with the smaller monofunctional chorismate mutases, like that of $M$. jannaschii, and is the only possible start codon. The promoter region and the $\operatorname{aro} Q$ gene were completely sequenced in the primer extension experiments and the

B.

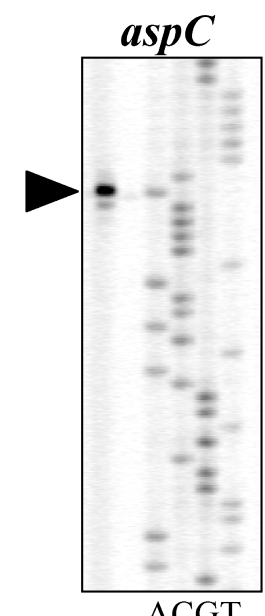

ACGT

C.

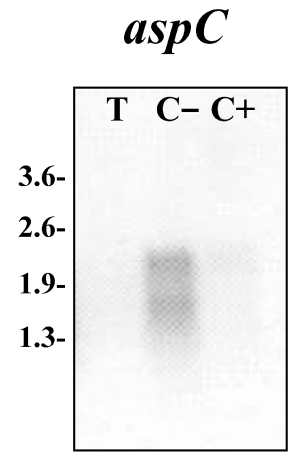

BRE TATA

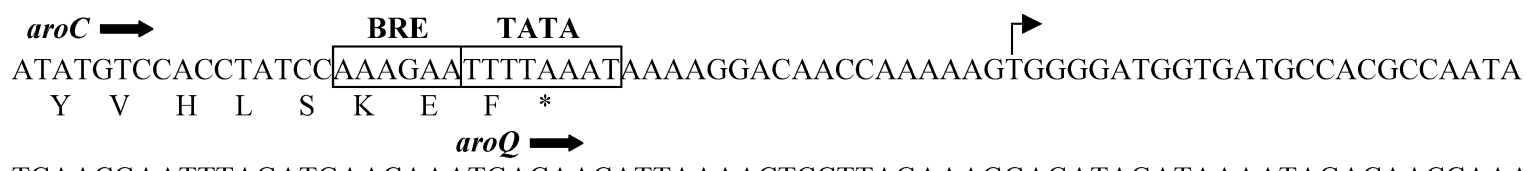

TCAACGAATTTAGATGAACAAATGACAACATTAAAACTCCTTAGAAAGGAGATAGATAAAATAGACAACCAAA $\begin{array}{lllllllllllllllll}M & \mathrm{~T} & \mathrm{~T} & \mathrm{~L} & \mathrm{~K} & \mathrm{~L} & \mathrm{~L} & \mathrm{R} & \mathrm{K} & \mathrm{E} & \mathrm{I} & \mathrm{D} & \mathrm{K} & \mathrm{I} & \mathrm{D} & \mathrm{N} & \mathrm{Q}\end{array}$ TAATATCTCTTCTAAAAAAGAGACTTGAAATAGCCCAAGCAATTGGGAAAATAAAGAAAGAGCTCAATCTCCC $\begin{array}{llllllllllllllllllllllll}\mathrm{I} & \mathrm{I} & \mathrm{S} & \mathrm{L} & \mathrm{L} & \mathrm{K} & \mathrm{K} & \mathrm{R} & \mathrm{L} & \mathrm{E} & \mathrm{I} & \mathrm{A} & \mathrm{Q} & \mathrm{A} & \mathrm{I} & \mathrm{G} & \mathrm{K} & \mathrm{I} & \mathrm{K} & \mathrm{K} & \mathrm{E} & \mathrm{L} & \mathrm{N} & \mathrm{L}\end{array}$ CATAGAAGATAGAAAAAGAGAAGAAGAAGTTCTAAGAAGAGCTGGCGAGTTTAGGGAAATTTTTGAAAAGAT $\begin{array}{lllllllllllllllllllllllllll}\mathrm{P} & \mathrm{I} & \mathrm{E} & \mathrm{D} & \mathrm{R} & \mathrm{K} & \mathrm{R} & \mathrm{E} & \mathrm{E} & \mathrm{E} & \mathrm{V} & \mathrm{L} & \mathrm{R} & \mathrm{R} & \mathrm{A} & \mathrm{G} & \mathrm{E} & \mathrm{F} & \mathrm{R} & \mathrm{E} & \mathrm{I} & \mathrm{F} & \mathrm{E} & \mathrm{K}\end{array}$ SD aspC $\longrightarrow$

TTT GGAGGTTAGCAAAGATGTTCAACGTTTATGAG

$\begin{array}{lllllllllllllllll}\text { I } & \mathrm{L} & \mathrm{E} & \mathrm{V} & \mathrm{S} & \mathrm{K} & \mathrm{D} & \mathrm{V} & \mathrm{Q} & \mathrm{R} & \mathrm{L} & * \\ & & & & & \mathrm{M} & \mathrm{F} & \mathrm{N} & \mathrm{V} & \mathrm{Y} & \mathrm{E}\end{array}$

Figure 4. (A) Northern analysis of the P. furiosus AspAT (aspC). Pyrococcus furiosus was grown in a chemically-defined medium with cellobiose as the carbon source in the presence $(\mathrm{C}+)$ or absence $(\mathrm{C}-$ ) of the aromatic amino acids, or with tryptone $(\mathrm{T})$. (B) Identification of the transcriptional start site for the $a s p C$ by primer extension analysis, indicated by the arrow. (C) The transcriptional start site as determined by primer extension analysis is designated by an arrow. The TATA and BRE sequences are boxed. 
sequences are in excellent agreement with the genome sequencing project, thereby ruling out the possibility of a frame shift.

\section{Discussion}

The AspAT from $P$. furiosus is distinct from the other archaeal and thermophilic AspATs because of its relatively broad substrate specificity with both amino and $\alpha$-keto acids, and its metabolic role. The enzymes from Methanococcus aeolicus, Thermus thermophilus and the halophilic archaeon Haloferax mediterrane $i$ are all specific for aspartate and appear to be involved in the catabolism of aspartate (Marino et al. 1988, Muriana et al. 1991, Xing and Whitman 1992, Okamoto et al. 1996). The AspAT from S. solfataricus is similar to the $P$. furiosus enzyme in that it shares similar substrate specificity regarding the amino acids and is capable of using pyruvate as an amino acceptor, but appears to be involved in the catabolism of aspartate (Marino et al. 1988). Except that the AspAT activity in crude extracts from $S$. solfataricus and M. aeolicus was identical regardless of the carbon or nitrogen source, little is known about the regulation of these enzymes.

The biosynthesis of the aromatic amino acids in $P$. furiosus appears to occur by way of the classical shikimate pathway based on the genes present on the chromosome. The argument that AspAT is involved solely in the biosynthesis of the aromatic amino acids is supported by several observations. The gene encoding AspAT is located between the aro and trp operons, which collectively encode the genes necessary for the biosynthesis of the aromatic amino acids phenylalanine, tyrosine and tryptophan. In addition, aspC is expressed when $P$. furiosus is grown in the absence of the aromatic amino acids. In contrast, expression of $a s p C$ is not observed in the presence of proteinaceous substrates such as yeast extract and tryptone, thereby ruling out a catabolic role during proteolytic fermentation. Recently a similar mode of regulation has been shown with the trp operon in Thermococcus kodakaraensis KOD1 in which expression was tryptophan-dependent and was induced when the cells were grown in the absence of the amino acid (Tang et al. 1999). The broad substrate specificity of the pyrococcal enzyme is also ideally suited for amino acid biosynthesis because it is capable of utilizing a number of amino acids as amino donors for the biosynthesis of aromatic amino acids. This broad specificity of AspAT has also been observed in one other organism, Trypanosoma cruzi (Montemartini et al. 1993). It has been proposed that these broadspecificity enzymes may be the closest relative to the last common ancestor for the aminotransferase superfamily, also referred to as a contemporary "dinosaur” (Jensen and Gu 1996).

In T. litoralis and M. aeolicus there are two AroATs, and a similar situation is observed in P. furiosus (Xing and Whitman 1992, Andreotti et al. 1994). In all three organisms, both of the AroATs are specific for the aromatic amino acids; in addition, the AroAT I and AroAT II enzymes of the three organisms have similar kinetic features. A significant difference between these AroATs is found in the regulation of their transcription. The AroAT I was expressed under all conditions tested and the highest levels of expression were found when cells were grown with tryptone as the primary carbon and energy source. It is likely that the AroAT I is the dominant aminotransferase involved in the catabolism of the aromatic amino acids. However, an alternative metabolic role cannot be excluded because significant amounts of the $t y r B$ transcript were present in all growth conditions tested, and it is not uncommon to see aminotransferases with overlapping activities and metabolic functions (Whitaker et al. 1982). Likewise, AroAT II has a low basal level of expression, which appears to be slightly induced in the presence of tryptone. Another alternative is that the AroAT II is active, and possibly induced by a yet to be identified substrate. It has been shown that the P. horikoshii AroAT II homolog was also active with aliphatic substrates, with maximal activity with the 8 -carbon substrate 2 -amino octanoic acid (Matsui et al. 2000). It is possible that the true substrate for the AroAT II has not yet been identified.

There are now four distinct aminotransferases that have been identified and characterized in P. furiosus, all of which belong to Subfamily I: AlaAT, AroAT I, AroAT II and AspAT. Aminotransferases play crucial roles in the fermentative metabolism of $P$. furiosus and are involved in energy production and biosynthesis (catabolism and anabolism; this work), as well as in the maintenance of the redox balance in the cell (Ward et al. 2000). Each aminotransferase appears to play distinct metabolic roles and is regulated differently. Details on the regulatory mechanisms of the modulation of aminotransferase expression as reported in this study, however, remain to be elucidated.

\section{Acknowledgments}

The research was partly supported by the EU BIOTECH (Contract BIO2-CT93-0274).

\section{References}

Andreotti, G., M.V. Cubellis, G. Nitti, G. Sannia, X. Mai, M.W.W. Adams and G. Marino. 1995. An extremely thermostable aromatic aminotransferase from the hyperthermophilic archaeon Pyrococcus furiosus. Biochim. Biophys. Acta. 1247:90-96.

Andreotti, G., M.V. Cubellis, G. Nitti, G. Sannia, X. Mai, G. Marino and M.W.W. Adams. 1994. Characterization of aromatic aminotransferases from the hyperthermophilic archaeon Thermococcus litoralis. Eur. J. Biochem. 220:543-549.

Bell, S.D., P.L. Kosa, P.B. Sigler and S.P. Jackson. 1999. Orientation of the transcription preinitiation complex in archaea. Proc. Natl. Acad. Sci. 96:13,662-13,667.

Christen, P. and D. Metzler. 1985. Transaminases. John Wiley, New York.

Fiala, G. and K.O. Stetter. 1986. Pyrococcus furiosus sp. nov. represents a novel genus of marine heterotrophic archaebacteria growing optimally at $100^{\circ} \mathrm{C}$. Arch. Microbiol. 161:168-175.

Gonzalez, J.M., Y. Masuchi, F.T. Robb, J.W. Ammerman, D.L. Maeder, M. Yanagibayashi, J. Tamaoka and C. Kato. 1998. Pyrococcus horikoshii sp. nov., a hyperthermophilic archaeon isolated from a hydrothermal vent at the Okinawa Trough. Extremophiles 2:123-130. 
Hayashi, H., K. Inoue, T. Nagata, S. Kuramitsu and H. Kagamiyama. 1993. Escherichia coli aromatic amino acid aminotransferase: characterization and comparison with aspartate aminotransferase. Biochemistry 32:12,229-12,239.

Jensen, R.A. and W. Gu. 1996. Evolutionary recruitment of biochemically specialized subdivisions of family I within the protein superfamily of aminotransferases. J. Bacteriol. 178:2161-2171.

Kengen, S.W., E.J. Luesink, A.J.M. Stams and A.J. Zehnder. 1993. Purification and characterization of an extremely thermostable $\beta$-glucosidase from the hyperthermophilic archaeon Pyrococcus furiosus. Eur. J. Biochem. 213:305-312.

Kengen, S.W.M., A.J.M. Stams and W.M. de Vos. 1996. Sugar metabolism of hyperthermophiles. FEMS Microbiol. Rev. 18:119-137.

MacBeath, G., P. Kast and D. Hilvert. 1998. A small, thermostable, and monofunctional chorismate mutase from the archaeon Methanococcus jannaschii. Biochemistry 37:10,062-10,073.

Mai, X. and M.W. Adams. 1994. Indolepyruvate ferredoxin oxidoreductase from the hyperthermophilic archaeon Pyrococcus furiosus. A new enzyme involved in peptide fermentation. J. Biol. Chem. 269:16,726-16,732.

Mai, X. and M.W. Adams. 1996. Purification and characterization of two reversible and ADP-dependent acetyl coenzyme A synthetases from the hyperthermophilic archaeon Pyrococcus furiosus. J. Bacteriol. 178:5897-5903.

Marino, G., G. Nitti, M.I. Arnone, G. Sannia, A. Gambacorta and M. De Rosa. 1988. Purification and characterization of aspartate aminotransferase from the thermoacidophilic archaebacterium Sulfolobus solfataricus. J. Biol. Chem. 263:12,305-12,309.

Matsui, I., E. Matsui, Y. Sakai, H. Kikuchi, Y. Kawarabayasi, H. Ura, S. Kawaguchi, S. Kuramitsu and K. Harata. 2000. The molecular structure of hyperthermostable aromatic aminotransferase with novel substrate specificity from Pyrococcus horikoshii. J. Biol. Chem. 275:4871-4879.

McPhalen, C.A., M.G. Vincent and J.N. Jansonius. 1992. X-ray structure refinement and comparison of three forms of mitochondrial aspartate aminotransferase. J. Mol. Biol. 225:495-517.

Mehta, P.K., T.I. Hale and P. Christen. 1993. Aminotransferases: demonstration of homology and division into evolutionary subgroups. Eur. J. Biochem. 214:549-561.

Montemartini, M., J.A. Santome, J.J. Cazzulo and C. Nowicki. 1993. Purification and partial structural and kinetic characterization of tyrosine aminotransferase from epimastigotes of Trypansoma cruzi. Biochem. J. 292:901-906.
Muriana, F.J., M.C. Alvarez Ossorio and A.M. Relimpio. 1991. Purification and characterization of aspartate aminotransferase from the halophile archaebacterium Haloferax mediterranei. Biochem J. 278:149-154.

Nobe, Y., S. Kawaguchi, H. Ura, T. Nakai, K. Hirotsu, R. Kato and S. Kuramitsu. 1998. The novel substrate recognition mechanism utilized by aspartate aminotransferase of the extreme thermophile Thermus thermophilus HB8. J. Biol. Chem. 273:29,554-29,564.

Okamoto, A., T. Higuchi, K. Hirotsu, S. Kuramitsu and H. Kagamiyama. 1994. X-ray crystallographic study of pyridoxal 5'-phosphate-type aspartate aminotransferases from Escherichia coli in open and closed form. J. Biochem. (Tokyo) 116:95-107.

Okamoto, A., R. Kato, R. Masui, A. Yamagishi, T. Oshima and S. Kuramitsu. 1996. An aspartate aminotransferase from an extremely thermophilic bacterium, Thermus thermophilus HB8. J. Biochem. (Tokyo) 119:135-144.

Oue, S., A. Okamoto, Y. Nakai, M. Nakahira, T. Shibatani, H. Hayashi and H. Kagamiyama. 1997. Paracoccus denitrificans aromatic amino acid aminotransferase: a model enzyme for the study of dual substrate recognition mechanism. J. Biochem. (Tokyo) 121: 161-171.

Paris, C.G. and B. Magasanik. 1981. Purification and properties of aromatic amino acid aminotransferase from Klebsiella aerogenes. J. Bacteriol. 145:266-271.

Tang, X., S. Ezaki, S. Fujiwara, M. Takagi, H. Atomi and T. Imanaka. 1999. The tryptophan biosynthesis gene cluster $\operatorname{trpCDEGFBA}$ from Pyrococcus kodakaraensis KOD1 is regulated at the transcriptional level and expressed as a single mRNA. Mol. Gen. Genet. 262:815-821.

Ward, D.E., S. Kengen, J. van der Oost and W.M. de Vos. 2000. Purification and characterization of the alanine aminotransferase from the hyperthermophilic archaeon Pyrococcus furiosus and its role in alanine production. J. Bacteriol. 182:2559-2566.

Watrin, L., V. Martin Jezequel and D. Prieur. 1995. Minimal amino acid requirements of the hyperthermophilic archaeon Pyrococcus abyssi, isolated from deep-sea hydrothermal vents. Appl. Environ. Microbiol. 61:1138-1140.

Whitaker, R.J., C.G. Gaines and R.A. Jensen. 1982. A multispecific quintet of aromatic aminotransferases that overlap different biochemical pathways in Pseudomonas aeruginosa. J. Biol. Chem. 257:13,550-13,556.

Xing, R.Y. and W.B. Whitman. 1992. Characterization of amino acid aminotransferases of Methanococcus aeolicus. J. Bacteriol. 174: $541-548$. 

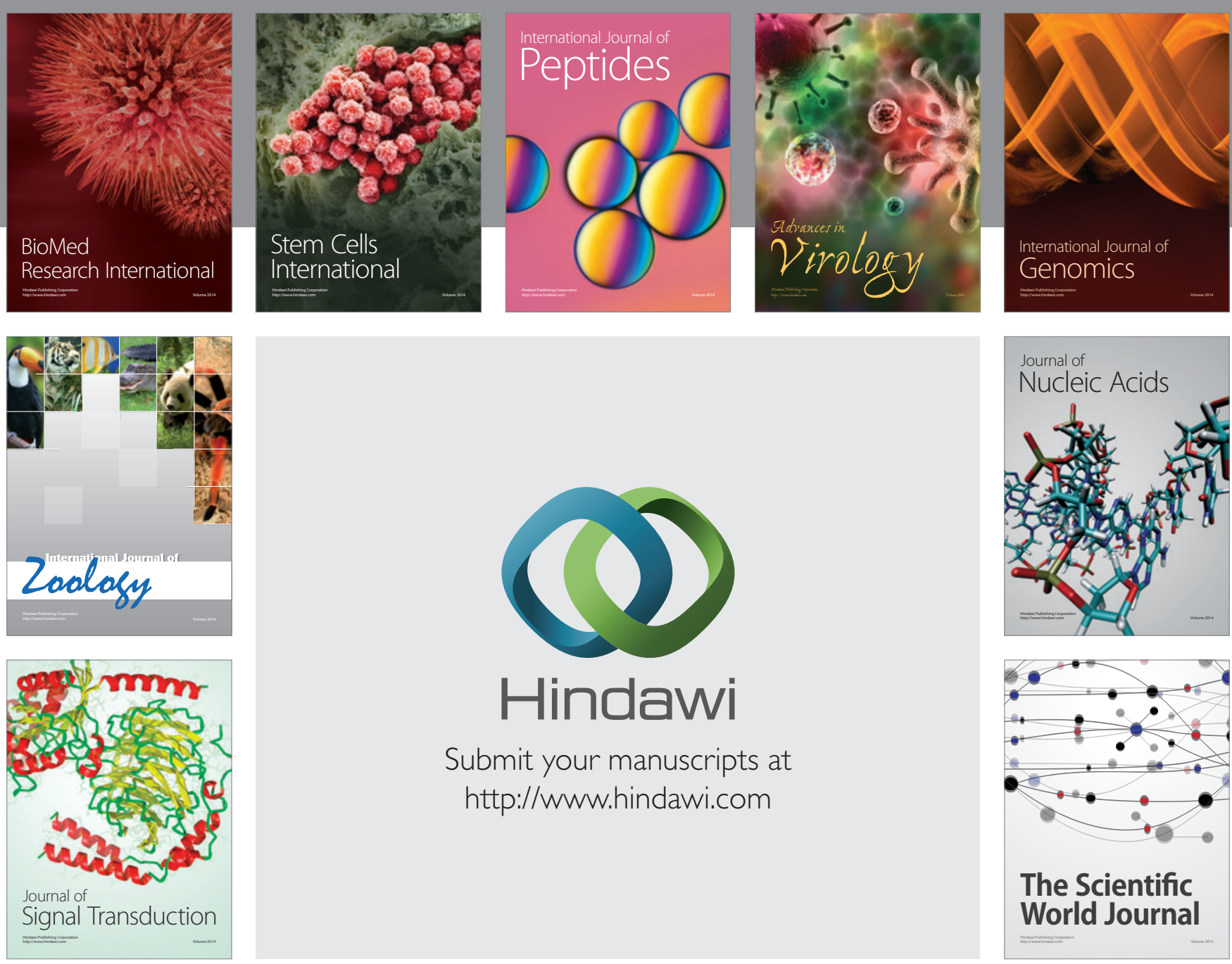

Submit your manuscripts at

http://www.hindawi.com
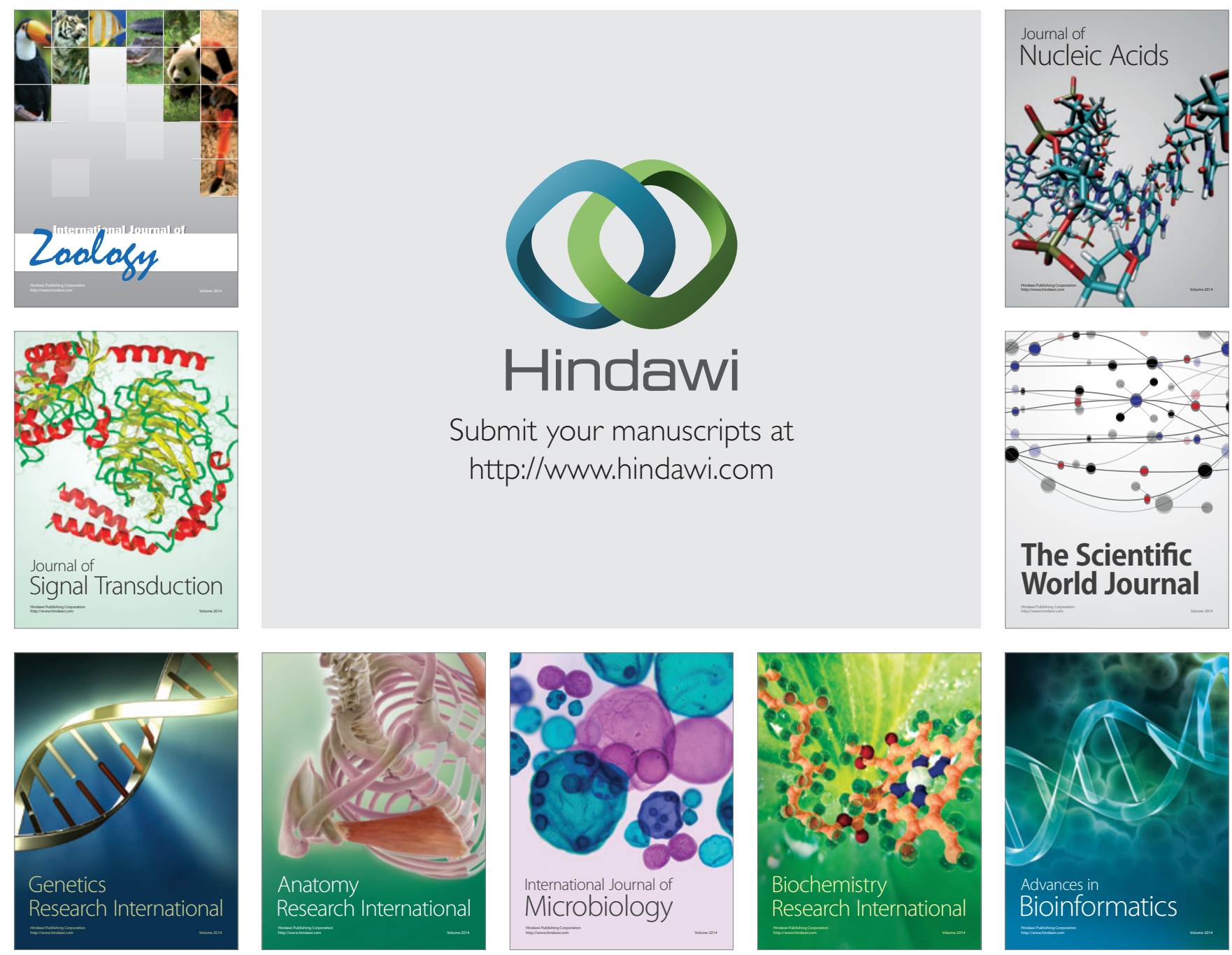

The Scientific World Journal
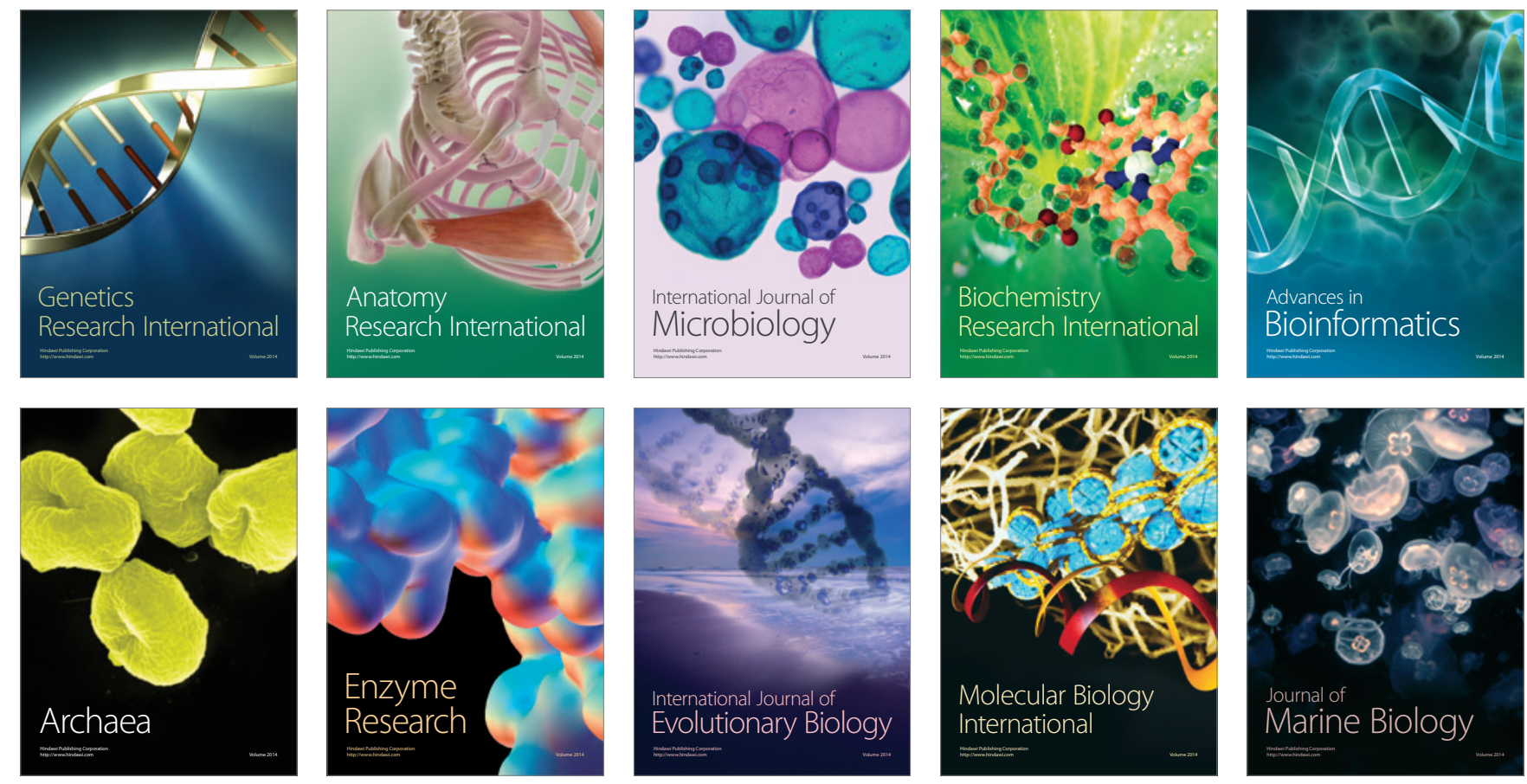